\title{
A WebGIS-Based Information System for Monitoring and Warning of Geological Disasters for Lanzhou City, China
}

\author{
Fang Miao and Qi Yuan \\ Cold and Arid Regions Environmental and Engineering Research Institute, Chinese Academy of Sciences (CAS), \\ Lanzhou 730000, China \\ Correspondence should be addressed to Qi Yuan; qiyuan@lzb.ac.cn
}

Received 5 September 2013; Revised 6 November 2013; Accepted 27 November 2013

Academic Editor: Chung-Ru Ho

Copyright (C) 2013 F. Miao and Q. Yuan. This is an open access article distributed under the Creative Commons Attribution License, which permits unrestricted use, distribution, and reproduction in any medium, provided the original work is properly cited.

Monitoring and warning of geological disasters accurately and in a timely fashion would dramatically mitigate casualties and economic losses. This paper takes Lanzhou city as an example and designs a Web-based system, namely the information system for geological disaster monitoring and warning (ISGDMW). Presented are its framework, key developing technologies, database, and working flow. The information system adopts a Browser/Server (B/S) structure and has three-tier architecture, combining insitu monitoring instruments, the wireless sensor network, WebGIS techniques and the grey system theory. The framework of the ISGDMW can be divided into three categories: (1) in-situ monitoring system, it aims to monitor geological disaster sites and get state information of geological disaster sites; (2) database, manage in-situ monitoring data, antecedent field investigating data and basic data; (3) analyzing and warning system, analyze in-situ monitoring data, understand the deformation trend of the potential geological disaster, and release disaster warning information to the public. The ISGDMW allow the processes of geological disaster monitoring, in-situ monitoring data analysis, geological disaster warning to be implemented in an efficient and quick way, and can provide scientific suggestions to commanders for quick response to the possibility of geological disaster.

\section{Introduction}

To mitigate geological disaster, we should depend on both real-time in situ data and quick response to the possibility of geological disaster. WebGIS is the integrated product of geographic information system (GIS) and internet technologies; in WebGIS, the internet technologies are connected with GIS in order to take advantage of their special characteristics, such as easy usability, use of the GIS data such as input, adjustment, manipulation, analysis, and output of geographical information and to bring out related service on the internet. Whereas previous standalone GIS had restricted application capability on the network, the WebGIS makes it possible to retrieve and analyze spatial data through the web. The internet also provides a medium for processing georelated information with no location restrictions [1]. In addition, WebGIS promotes the sharing and synthesis of multisource data and enables widespread sharing of spatial data and geosciences models [2]. Therefore, WebGIS offers a powerful and advanced approach to prevent and mitigate geological disaster, and it has played a significant role in terms of transmitting catastrophe data, analyzing the disaster condition, and releasing disaster information [3-7]. In situ monitoring data can be used to grasp the deformation trend of the geological disaster; therefore, in situ monitoring instruments (e.g., inclinometers, rain gauges, piezometers, and extensometers) must be playing an important role in the process of geological disaster mitigation [7-10].

In this paper, we comprehensively utilize the advantages of in situ monitoring instruments, the wireless sensor network, and WebGIS techniques in terms of in situ monitoring, transmitting data, disaster analysis, and data management to design a Web-based system, namely, the information system for geological disaster monitoring and warning (ISGDMW). Deformation trends of the landslide and debris flow are analyzed automatically with the grey system method and threshold rainfall, respectively, based on ISGDMW. ISGDMW is a novel platform and is designed to improve practical efficiency of geological disaster mitigation in Lanzhou city. 


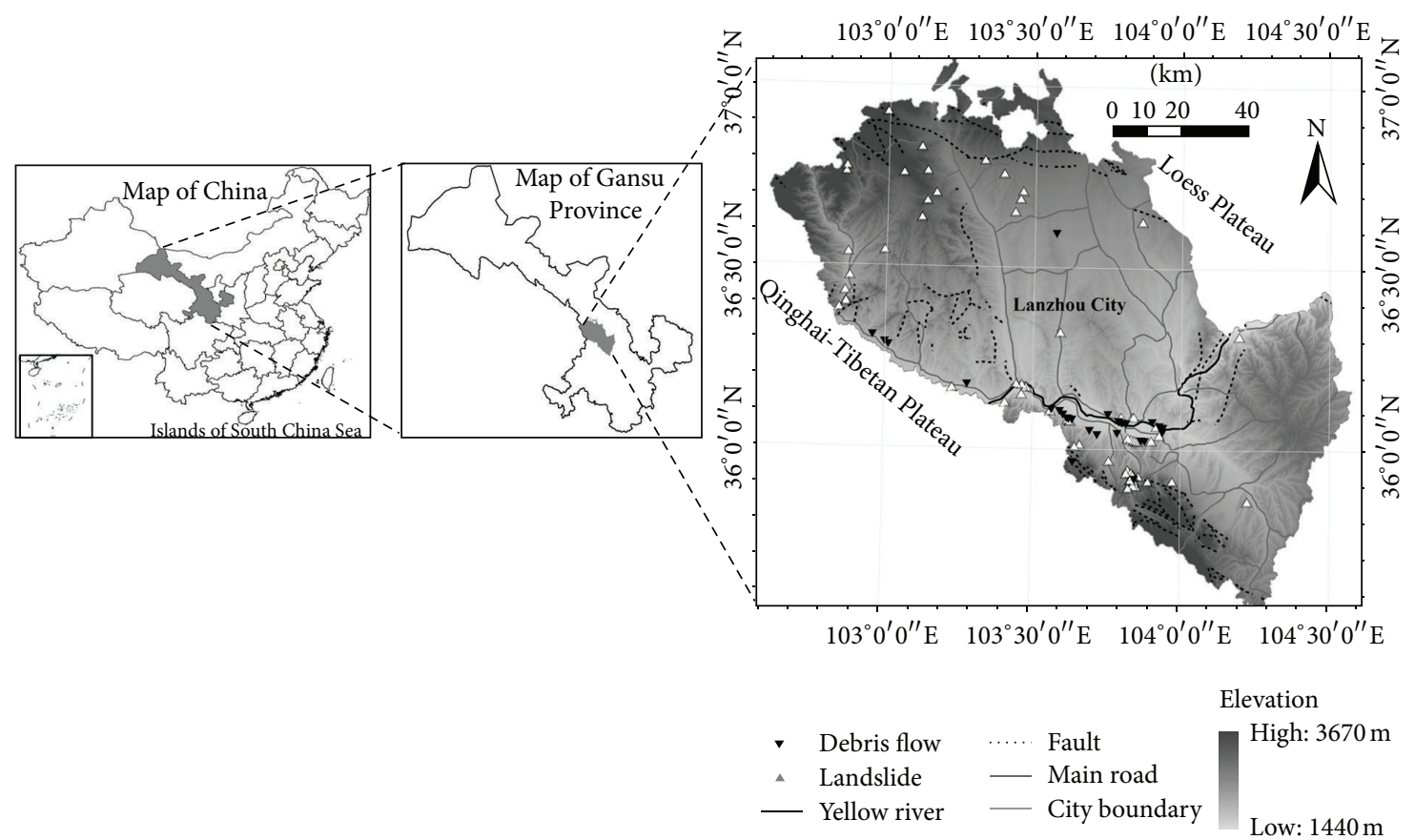

FIGURE 1: The study area, landslide sites, and debris flow sites with high risk were investigated and supplied by the Lanzhou Bureau of Land and Resources.

\section{Study Area}

Lanzhou city is located in the transitional zone between the Qinghai-Tibet Plateau and the Loess Plateau (Figure 1). In this area, geological conditions are very complex, and some deep and large gullies exist in most parts of the territory. These geological and geographic backgrounds lead to Lanzhou being prone to landslides and debris flow disasters. The latest statistics [11] show that the existing landslide sites (including unstable slopes) number 417 in Lanzhou. In addition, in Lan zhou, the rainfall from April to September accounts for about $86.8 \%$ of the annual precipitation [11] and always occurs in the form of heavy rain and storms. This pattern of rainfall is consistent with the fact that landslide disasters and debris flow always occur during the months of April to September in Lanzhou. In the last 5 years (from 2008 to 2012), 16 serious landslide disasters broke out in this city; each landslide disaster caused economic losses of more than 0.1 million CNY; 14 among the 16 serious landslide disasters were triggered by heavy rainfall and the other 2 landslide disasters were triggered by snow and ice melt; detailed presentation is shown in Table 1. At 18:00 Beijing standard time, May 16, 2009, the most serious landslide disaster occurred at Jiuzhou district in Lanzhou. This landslide disaster caused the death of 7 people and the 1 person injury of, and the direct economic loss of 20.6 million CNY was recorded. The Jiuzhou landslide belongs to loess landslide category. The length and width of Jiuzhou landslide were 160 and 40 meters, respectively, and covered an area of about $7500 \mathrm{~m}^{2}$ with an average depth of about 4.0 meters. The total volume was about $6.2 \times 10^{4} \mathrm{~m}^{3}$. Figure 2 demonstrates the front view of the Jiuzhou landslide.

\section{Landslide and Debris Flow Forecasting Method}

3.1. Grey System Forecasting of Landslide Deformation. The grey system theory was initiated by Deng [12]. The concept of the grey system, in its theory and successful application, is now well known in China. It is able to (1) analyze the indeterminate and incomplete data to establish the systematic relations [13] and (2) forecast time series accurately and this has been quite a popular subject for researchers both in the past and at present [14]. It assumes that the internal structure, parameters, and characteristics of the observed system are unknown. The system state can be predicted by a differential equation from the recent historical measurements [13]. Although the historical measurements are too complex or chaotic, they always contain some governing laws [14]. The grey prediction has been widely used in applications of geography [15], agriculture [16], runoff prediction [17], displacement prediction of landslide [18], prediction of slope stability [19], power demand [20], stock market [21], and so forth. This theory is also coupled with the WebGIS to forecast timely deformation in the field of engineering geology, such as the deformation of landslides and host rock in the cavity [7].

The model GM $(1,1)$, one of the grey models, is the most widely used in the literature, pronounced as "grey model first order one variable". This model is a time series forecasting model. The differential equations of the GM (1, 1) model have time varying coefficients. In other words, the model is renewed as the new data become available to the prediction model. The GM $(1,1)$ model can only be used in positive data sequences [22]. In this paper, since all 
TABLE 1: Serious landslide disaster records in Lanzhou from 2008 to 2012. It was recorded and supplied by the Lanzhou Bureau of Land and Resources.

\begin{tabular}{|c|c|c|c|c|}
\hline Occurrence date & Site & Trigger factor & Casualties & Economic losses (0.1 million CNY) \\
\hline March 28, 2008 & Chengguan district & Snow and ice melt & 1 & 20.0 \\
\hline July 18, 2008 & Gaolan county & Rainfall & 1 & 10.0 \\
\hline September 19, 2008 & Gaolan county & Rainfall & & 50 \\
\hline May 16, 2009 & Chengguan district & Rainfall & 8 & 2060.0 \\
\hline September 14, 2009 & Chengguan district & Rainfall & 3 & 80.0 \\
\hline September 15, 2009 & Qilihe district & Rainfall & & 30.0 \\
\hline October 22, 2009 & Qilihe district & Rainfall & & 130.0 \\
\hline August 16, 2010 & Honggu district & Rainfall & & 10 \\
\hline October 19, 2010 & Chengguan district & Rainfall & & 10 \\
\hline April 26, 2011 & Xigu district & Rainfall & & 100 \\
\hline August 29, 2011 & Yuzhong county & Rainfall & & 16 \\
\hline October 8, 2011 & Xigu district & Rainfall & & 86 \\
\hline March 17, 2012 & Chengguan district & Snow and ice melt & & 600 \\
\hline April 20, 2012 & Yuzhong county & Rainfall & & 30 \\
\hline May 21, 2012 & Chengguan district & Rainfall & & 50 \\
\hline May 21, 2012 & Chengguan district & Rainfall & & 100 \\
\hline
\end{tabular}

*Source from Lanzhou Bureau of Land and Resources.

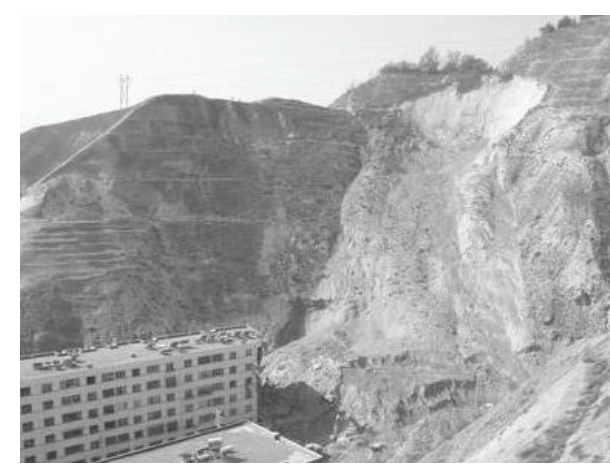

(a)

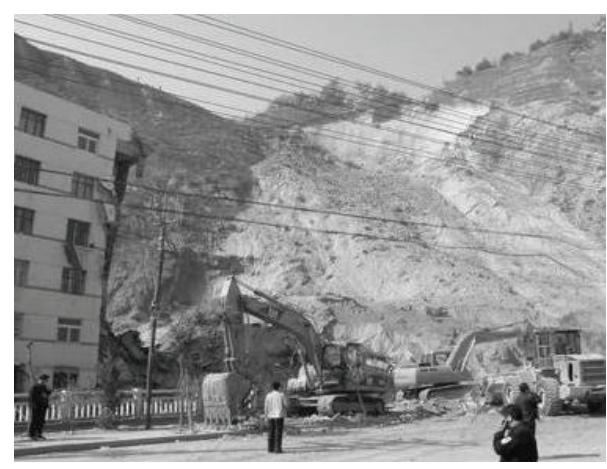

(b)

Figure 2: Jiuzhou landslide outburst at 18:00 Beijing standard time, May 16, 2009. The left image is the remote viewing of Jiuzhou landslide; the right image is the close viewing of Jiuzhou landslide.

the primitive data points are positive, grey models can be used to forecast the trend of deformation of landslide in this paper. [23].

The basic procedure for grey prediction is listed as follows

Step 1. Construct a data series that contains the recently measured displacement of a landslide:

$$
\begin{aligned}
z^{(0)} & =\left\{z^{(0)}(1), z^{(0)}(2), \ldots, z^{(0)}(n)\right\} \\
& =\left\{z^{(0)}(k) ; k=1,2, \ldots, n\right\}
\end{aligned}
$$

where $z^{(0)}(k)$ is the measurement from sensory information at time $k$ and $n$ is the length of the data series.
Step 2. Form a new data series $z^{(1)}$ by an accumulated generating operation (AGO):

$$
\begin{aligned}
z^{(1)} & =\left\{z^{(1)}(1), z^{(1)}(2), \ldots, z^{(1)}(n)\right\} \\
& =\left\{z^{(1)}(k) ; k=1,2, \ldots, n\right\},
\end{aligned}
$$

where

$$
z^{(1)}(k)=\left\{\sum_{i=1}^{k} z^{(0)}(i), k=1,2, \ldots, n\right\} .
$$

Step 3. Form the grey differential equation

$$
\frac{d z^{(1)}}{d t}+a z^{(1)}=b
$$


with initial condition $z^{(1)}(1)=z^{(0)}(1)$. The coefficients, $a$ and $b$, can be obtained by using the least square method, as shown in

$$
\widehat{a}=\left[\begin{array}{l}
a \\
b
\end{array}\right]=\left(B^{T} B\right)^{-1} B^{T} Y,
$$

where

$$
B=\left[\begin{array}{cc}
-Z^{(1)}(2) & 1 \\
-Z^{(1)}(3) & 1 \\
\ldots & \ldots \\
-Z^{(1)}(n) & 1
\end{array}\right], \quad Y=\left[\begin{array}{c}
z^{(0)}(2) \\
z^{(0)}(3) \\
\ldots \\
z^{(0)}(n)
\end{array}\right]
$$

$Z^{(1)}(k)=\alpha z^{(1)}(k)+(1-\alpha) z^{(1)}(k-1), k=2,3, \ldots n$, and $\alpha$ is the weighting factor, according to relevant literature [13]; in this paper, we specify $\alpha$ is a constant with 0.5 .

Step 4 (obtain the prediction value). Once $a$ and $b$ in (4) are obtained, the grey differential equation can be used to predict the value of state $z$ at time instant $k+1$.

The AGO grey prediction model can be obtained:

$$
\widehat{z}^{(1)}(k+1)=\left[z^{(0)}(1)-\frac{b}{a}\right] e^{-a k}+\frac{b}{a}, \quad k=0,1, \ldots
$$

Then the prediction value of the state can be calculated by an inverse accumulated generating operation (IAGO):

$$
\begin{aligned}
\widehat{z}^{(0)}(k+1) & =\widehat{z}^{(1)}(k+1)-\widehat{z}^{(1)}(k) \\
& =\left(1-e^{-a}\right)\left[z^{(0)}(1)-\frac{b}{a}\right] e^{-a k} .
\end{aligned}
$$

For instance, the following figure (Figure 3 ) that includes 13 ensembles, the former 11 ensembles which represent the measured displacement of a landslide and the latter 2 ensembles that represent the forecasted displacement of the landslide based on both the basic procedure of grey prediction theory and the measured displacement of the landslide.

3.2. Critical Rainfall of Debris Flow Forecasting. Real-time assessment of debris flow disaster is fundamental for building warning systems that can mitigate its risk. A convenient method to assess the possible occurrence of a debris flow is the comparison of measured and forecasted rainfall with rainfall threshold curves (RTC) [24]. Therefore, how to define the RTC is a key issue in order to prepare efficient forecasting in a mountainous region (e.g., Lanzhou) that is prone to raintriggered debris flow.

Rainfall, especially heavy rainfall, is the most critical natural triggering factor in Lanzhou. Rainfall intensity and duration of storms have been shown to influence the triggering of debris flows. The relationship between intense rainfall and debris flow initiation has been widely analyzed and documented in the literature in a number of different settings and environments throughout the world [25].

To define triggering thresholds, Bacchini and Zannoni [25] compared rainfall data to the occurrence of debris flows to examine the relations between debris flow initiation and

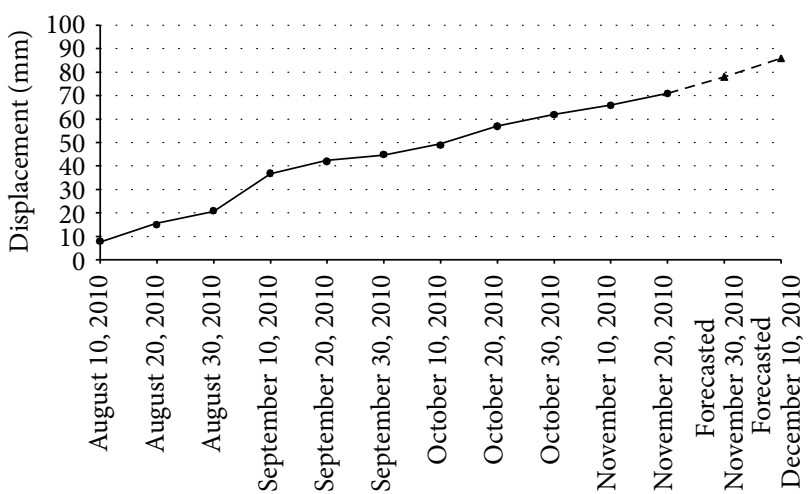

FIGURE 3: Data series of measured and forecasted displacements of a landslide, assuming that the current date is November 20, 2010, from August 10, 2010 to November 20, 2010; the landslide displacement meter measured a data series that contains 11 measured displacements of a landslide, based on the formulas (1)-(8) and 11 measured displacements. It can calculate and forecast landslide displacement value in the next 10 days (November 20, 2010November 30, 2010 and November 30, 2010-December 10, 2010). Black solid circles denote the measured displacement of a landslide; black solid triangle points denote the forecasted displacement of the landslide.

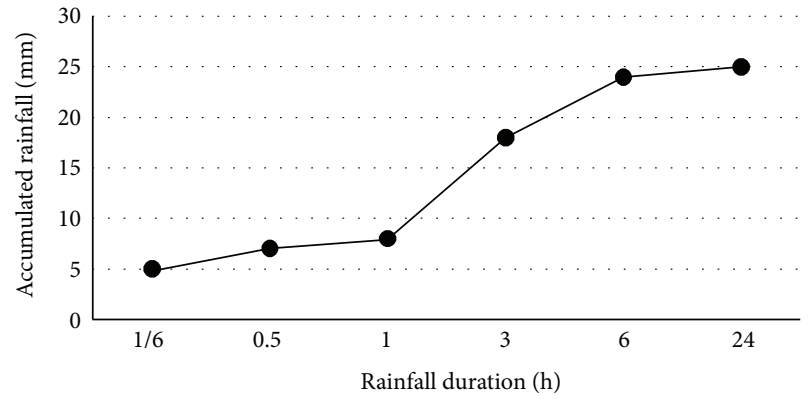

FIGURE 4: Rainfall threshold curve.

rainfall in the area of Cancia (Dolomites, Northeastern Italy). Tan and Duan [26] had studied the relation between debris flow initiation and minimum rainfall in China and preliminarily defined the RTC, but the result was not as accurate as possible due to the fact that it is a large-scale result. $\mathrm{Wu}$ et al. [27] considered that local condition, especially natural condition (e.g., precipitation, topography, and geology), is a key factor to assess this issue; simultaneously, other relevant studies [26] should not be neglected in the research. Under this methodology, Wu et al. [27] had identified the critical rainfall of debris flow initiation in Lanzhou. The new advance published by $\mathrm{Wu}$ et al. [27] is a local-scale result and as accurate as possible; thus, it is suitable to forecast debris flow in Lanzhou and be coupled with ISGDMW; detailed information about the new progress is presented in Table 2 and Figure 4.

According to Table 2, in Lanzhou city, the critical rainfall in 10 minutes, 30 minutes, 1 hour, 3 hours, 6 hours, and 24 hours is $5 \mathrm{~mm}, 7 \mathrm{~mm}, 8 \mathrm{~mm}, 18 \mathrm{~mm}, 24 \mathrm{~mm}$, and $25 \mathrm{~mm}$, respectively. RTC represents the relationship between rainfall 
TABLE 2: Critical rainfall to trigger debris flow in Lanzhou.

\begin{tabular}{lc}
\hline Rainfall duration $(\mathrm{h})$ & Accumulated rainfall $(\mathrm{mm})$ \\
\hline $1 / 6$ & 5 \\
0.5 & 7 \\
1 & 8 \\
3 & 18 \\
6 & 24 \\
24 & 25 \\
\hline
\end{tabular}

duration and critical rainfall. From Table 2, we plotted the RTC which is especially suitable for Lanzhou (Figure 4). When it rains, the algorithm of comparing the latest accumulated rainfall value measured by rain gauge and the rainfall threshold curve is implemented automatically in the analyzing module of ISGDMW. If the latest accumulated rainfall value is located above the curves, this debris flow site is considered to be dangerous. It is important to emphasize that Wu et al. [27] had only studied the relationship between rainfall duration and critical rainfall within 24 hours due to the shortage of data. So, in case the rainfall duration is over 24 hours, as long as the accumulated rainfall is greater than $25 \mathrm{~mm}$, the corresponding debris flow site is still considered to be dangerous; the same conclusion is also applicable to situation of rainfall duration being less than 10 minutes but the accumulated rainfall being more than $5 \mathrm{~mm}$.

\section{System Design}

4.1. Framework of ISGDMW. The framework of ISGDMW is shown in Figure 5 and can be divided into three parts.

(1) Part 1. In situ monitoring system: it mainly includes landslide monitoring instruments, debris flow monitoring instruments, and wireless sensor network. These monitoring instruments were installed into the geological disaster sites and get up-to-date information of geological disaster sites. In situ monitoring data should be transmitted to the data center and uploaded to the system database through the wireless sensor network.

(2) Part 2. Database: it is used for managing and integrating the spatial and nonspatial data related to geological disasters. Those data include in situ monitoring information, antecedent field investigating data, and basic data. In the database, the SQL Server2008 database software is often employed as a database platform, and the ArcSDE middleware, which is developed by ESRI Company, is chosen as the space database engine.

(3) Part 3. Analyzing and warning system: it consists of 4 modules: basic module, analyzing module, releasing module, and monitoring module; each module has a different function (please see detailed information in Figure 5). The core of analyzing and warning system is the analyzing module, the theoretical bases-the grey system; and rainfall threshold were coupled into the analyzing module, so it is the connection between the theoretical bases and ISGDMW. Analyzing and warning system mainly aims to analyze in situ monitoring data and the deformation of the potential geological disaster sites. Based on the grey system theory and measured displacement of landslide, deformation trend of landslide is analyzed automatically by ISGDMW, while the current state of debris flow is analyzed through comparing accumulated rainfall with the rainfall threshold. Finally, analyzed results (namely, output data from ISGDMW) and warning information will be released to the public through the internet, E-mail, and message based on the releasing module of ISGDMW.

4.2. Database of ISGDMW. Database of the ISGDMW is the fundamental component. On the one hand, it assists in management of the data related to geological disaster effectively, and on the other hand it provides data support for analyzing geological disaster conditions. The system database is divided into two categories, namely, spatial data and nonspatial data and can be demonstrated in Figure 6 particularly.

\section{(i) Spatial Data}

(1) Vector layers mainly include administrative maps, land-use/land-cover change maps (LUCC), road maps, soil maps, vegetation type maps, geology maps, fault and seismic belt maps, and river maps.

(2) Raster layers mainly include digital elevation model (DEM), slope gradient maps, and vegetation cover maps.

(3) Theme layers mainly include the field surveying map of potential geological disaster sites which are generated by antecedent field surveying tasks implemented by the Lanzhou Bureau of Land and Resources. In some of those potential geological disaster sites monitoring instruments will be installed in situ.

(ii) Nonspatial Data

(1) Monitoring data: it mainly includes rainfall data which is gathered from rain gauge and displacement data of landslide which is measured by a special instrument-displacement meter for landslide surface monitor. Those data are imported into the database through a wireless sensor network.

(2) Auxiliary data: it involves gross domestic product (GDP) and the population of every village or community. This data is the official reference to geological disaster preventing and control.

4.3. Working Flow of ISGDMW. According to the sequence of data acquirement, data analysis, and the releasing of warning information, the process of geological disaster mitigation and prevention based on the platform of ISGDMW can be designed in three stages and explained as follows (as shown in Figure 7). 


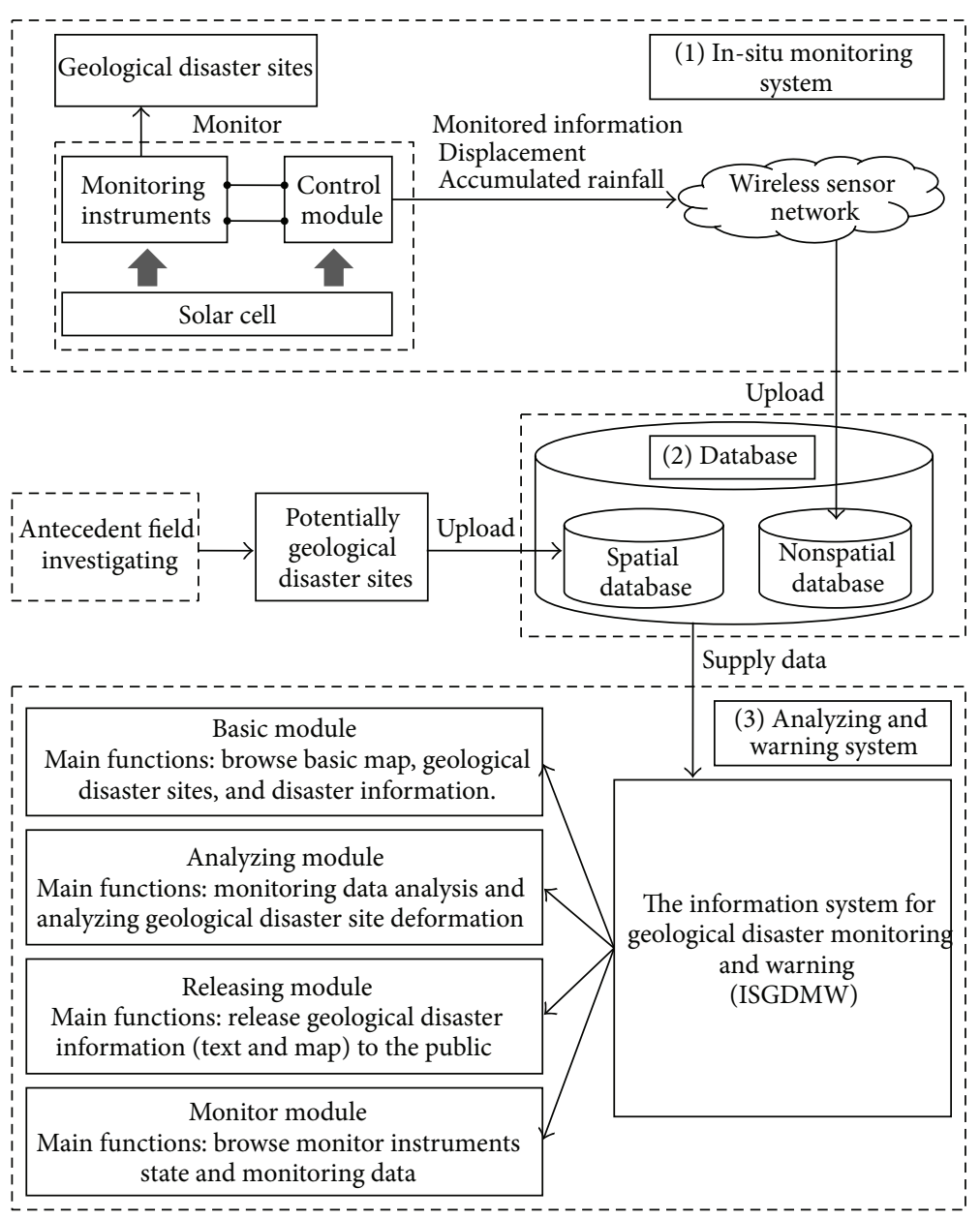

FIGURE 5: Framework of ISGDMW.

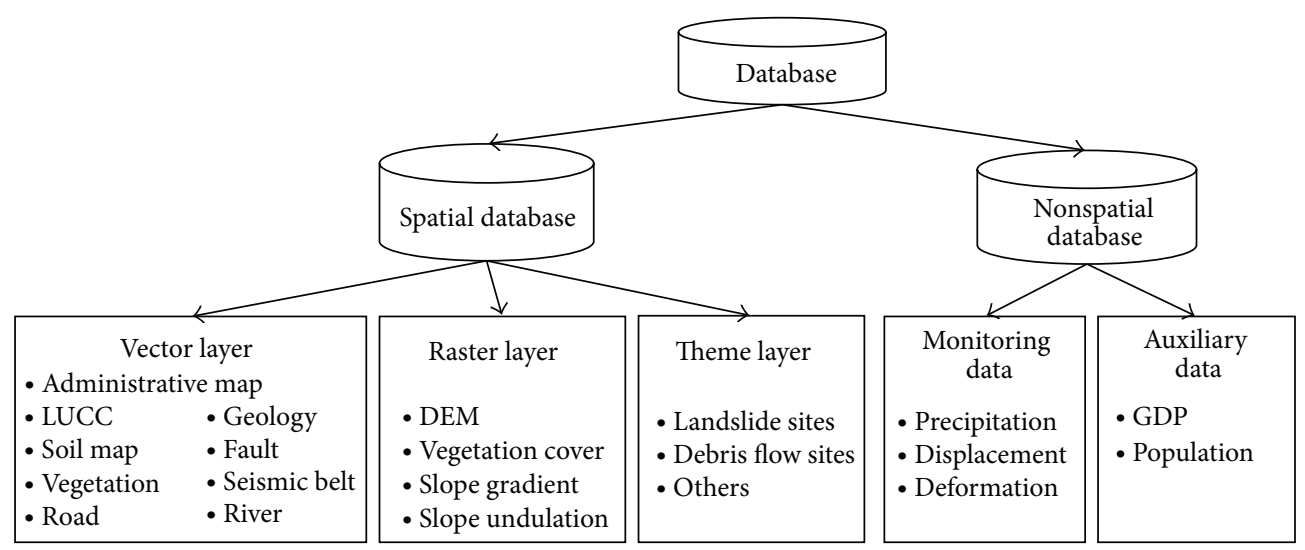

FIGURE 6: Architecture of database of ISDGMW.

(i) Stage One: In Situ Monitor and Upload Data. Landslide monitoring instruments automatically measure the displacement of landslides and wirelessly send the displacement value to the nonspatial database every 10 days; debris flow monitoring instruments automatically collect accumulated rainfall when it rains and then wirelessly send the accumulated rainfall value to the nonspatial database every 5 minutes. (ii) Stage Two: Analyze In Situ Data. The professional managers immediately start the analyzing module of SGDMW when the latest data from in situ monitoring instruments is inputed into the nonspatial database. Deformation trends of landslide are calculated by the grey system method which had been coupled with SGDMW, and calculated result is the displacement of landslide in the next 10 days. 


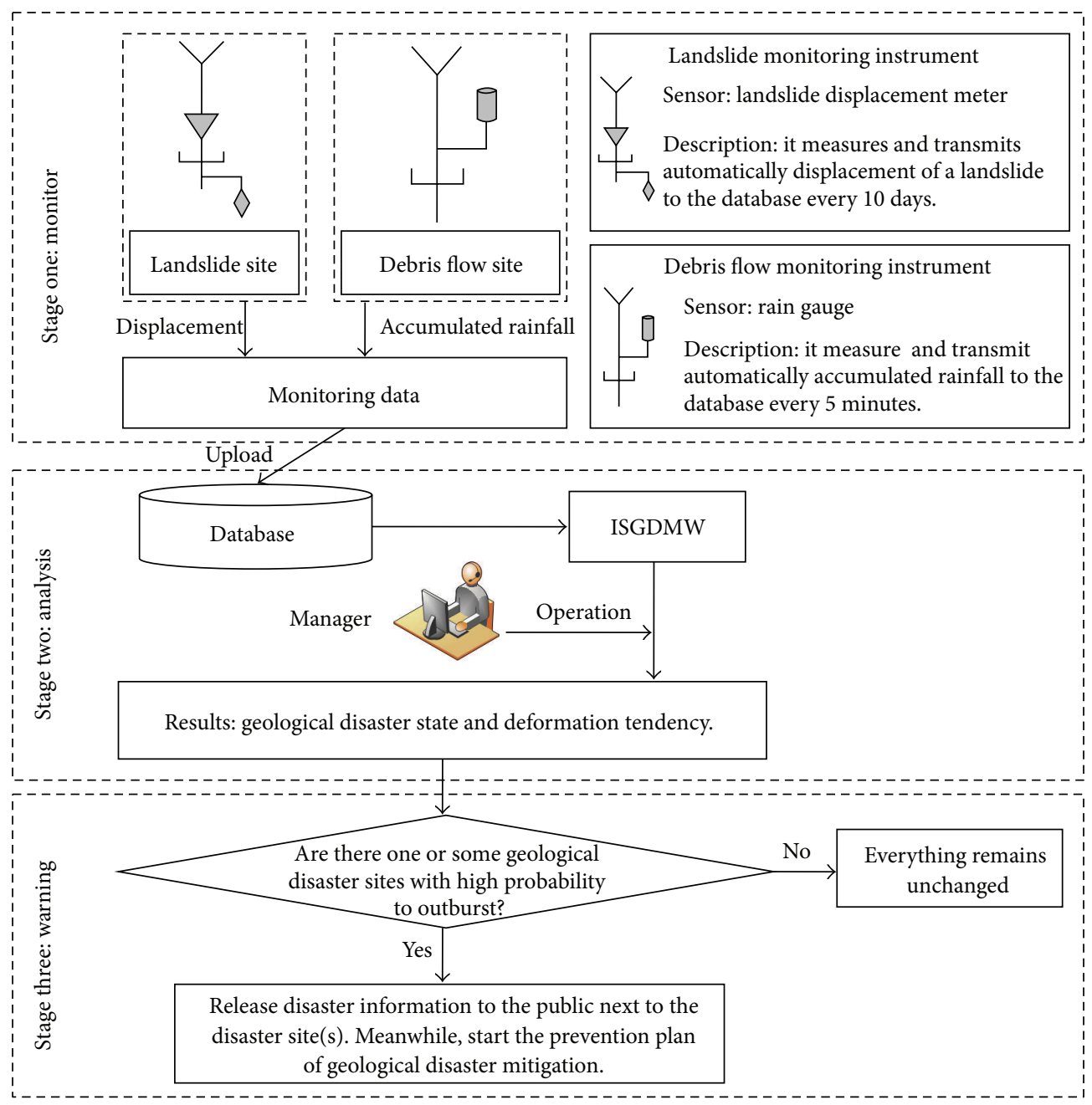

FIGURE 7: Working flow of geological disaster monitoring and warning based on ISGDMW.

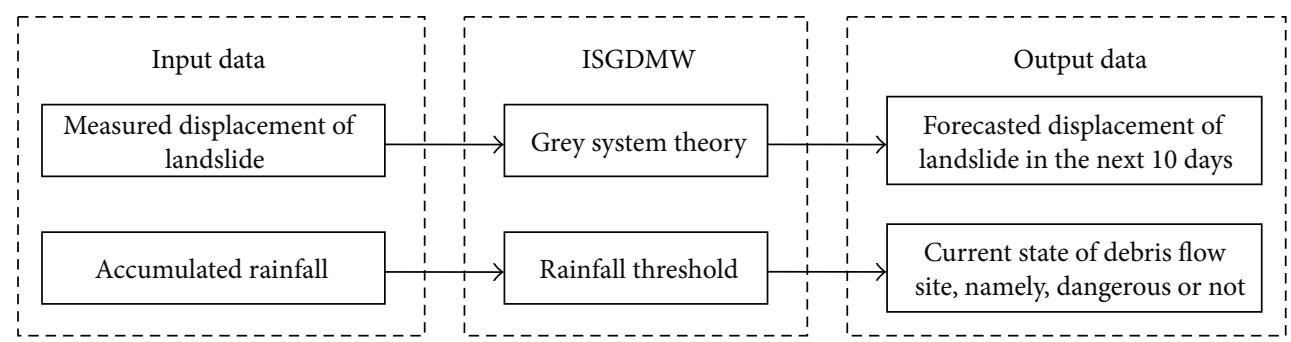

FIGURE 8: Data flow of stage two in the working flow of geological disaster monitoring and warning based on ISGDMW.

The current state of debris flow is analyzed by comparing the accumulated rainfall with the threshold rainfall of debris flow occurrence in Lanzhou; if the accumulated rainfall is more than the threshold rainfall of debris flow occurrence, then this debris flow site is considered as dangerous. That is to say, in this stage, the in situ monitoring instrument inputs measured displacement of landslide into the database and then the analyzing module of SGDMW automatically reads the measured displacement and forecasts the displacement of landslide in the next 10 days. The same process also occurs in analyzing the current state of debris flow. The data flow of this stage is shown in Figure 8.

(iii) Stage Three: Releasing Warning Information. For landslides and debris flows with sharp deformation or dangerous state, the professional manager must send warning messages to the governor who governs the region which is impacted by the geological disaster site(s) and release warning information on the internet through the analyzing module of SGDMW. 
When the governor receives a warning message, he or she must immediately alarm the public about the disaster warning message by means of oral announcement, broadcast, mobile phone, loudspeaker, sound the drum (or bell), sending out messengers, and so forth. Meanwhile, the governor must start prevention plans for the geological disaster and evacuate people from dangerous sites to safety shelters.

4.4. Developed Technology. The ISGDMW adopts a browser/ server structure based on a web service and can be divided into three tiers, namely, Data tier, Service tier, and Application tier. The users in Application tier are acting as terminals via the internet. Ordinary users such as the public could simply use internet browsers (IE or Firefox) to access the released information which the server provides. Other professional users such as professional managers could use more powerful desktop tools to access the server and perform sophisticated tasks [10]. In the Service tier, ArcGIS Server9.3 software which is one of the server GIS products from ESRI (Environmental Systems Research Institute, Inc.) was chosen as the basic platform for the server application, which can be used to introduce advanced GIS function to the internet environment and to publish information based on GIS. In the Data tier, SQL Server2008 software and ArcSDE9.3 software are used for managing and integrating the spatial and nonspatial data. The Dell server and Windows Server2008 operating system were used as the application environment of the system, and the ASP.net technology, MicrosoftVS2008.net developing environment, C\# programming language, and Dreamweaver software were chosen as the implementing means of the ISGDMW.

\section{Conclusions}

In general, geological disasters in the mountainous area are frequent and complex in China and in situ monitoring and a quick response are the key methods for mitigating geological disasters in those areas. In this paper, a WebGIS-based platform, that is, ISGDMW, has been designed to enable effective integration of in situ monitoring data management, geological disaster analysis, sending warning messages, and enabling a prompt response. The ISGDMW had been implemented and tentatively run during the past few months, but it still has a little bug in the codes and is kept in checking. We need to stress that our design scheme of the system is valuable for others because the system has three significant features, including simplicity, automation, and user friendliness. However, since the geological disaster is paroxysmal and complicated, ISGDMW must be further enhanced in two aspects, namely, in situ monitoring instruments and accurate analyzing methods, so as to more timely and accurately grasp the inner activity and state of every potential geological disaster site. Moreover, this highly advanced, easy-to-operate system can be considered as a prototype for developing geological monitoring and warning systems in other regions that are prone to geological disasters.

\section{Acknowledgments}

The authors thank all editors for supplying this chance and thank all viewers for their valuable suggestions and comments. This research was supported by the "Western light" Talent Project of the Chinese Academy of Sciences (no. Y028A11001).

\section{References}

[1] S. Verma, R. K. Verma, A. Singh et al., Advances in Computer Science, Engineering \& Applications, Springer, Berlin, Germany, 2012.

[2] C. Qu, H. Ye, and Z. Liu, "Application of WebGIS in seismological study," Acta Seismologica Sinica, vol. 24, no. 1, pp. 97-106, 2002.

[3] K. H. Kim, Y. Kawata, H. Kawakata, and R. Goto, "A study on the development and distribution of WebGIS-based flood hazard map," Journal of Japan Society for Natural Disaster Science, vol. 23, no. 4, pp. 539-551, 2005.

[4] F. Martinelli and C. Meletti, "A WebGIS application for rendering seismic hazard data in Italy," Seismological Research Letters, vol. 79, no. 1, pp. 68-78, 2008.

[5] V. Pessina and F. Meroni, "A WebGis tool for seismic hazard scenarios and risk analysis," Soil Dynamics and Earthquake Engineering, vol. 29, no. 9, pp. 1274-1281, 2009.

[6] F. C. Yu, C. Y. Chen, S. C. Lin, Y. C. Lin, S. Y. Wu, and K. W. Cheung, "A web-based decision support system for slopeland hazard warning," Environmental Monitoring and Assessment, vol. 127, no. 1-3, pp. 419-428, 2007.

[7] X. G. Li, A. M. Wang, and Z. M. Wang, "Stability analysis and monitoring study of Jijia River landslide based on WebGIS," Journal of Coal Science and Engineering, vol. 16, no. 1, pp. 41-46, 2010.

[8] S. Gabriele, G. D. Aquila, and F. Chiaravalloti, GeoSpatial Visual Analytics, Springer, Dordrecht, The Netherlands, 2009.

[9] L. Martino, C. Ulivieri, M. Jahjah, and E. Loret, "Remote sensing and GIS techniques for natural disaster monitoring," in Space Technologies for the Benefit of Human Society and Earth, pp. 331382, Springer, Dordrecht, The Netherlands, 2009.

[10] H. X. Lan, C. D. Martin, C. R. Froese et al., "A web-based GIS for managing and assessing landslide data for the town of Peace River, Canada," Natural Hazards and Earth System Science, vol. 9, no. 4, pp. 1433-1443, 2009.

[11] Z. Q. Ding and Z. H. Li, Geological Disaster and Prevention in Lanzhou City, Gansu Science and Technology Press, Lanzhou, China, 2009 (Chinese).

[12] J. L. Deng, "Control problems of grey systems," Systems and Control Letters, vol. 1, no. 5, pp. 288-294, 1982.

[13] J. F. Chen, Z. G. Shi, S. H. Hong, and K. S. Chen, "Grey prediction based particle filter for maneuvering target tracking," Progress in Electromagnetics Research, vol. 93, pp. 237-254, 2009.

[14] E. Kayacan, B. Ulutas, and O. Kaynak, "Grey system theorybased models in time series prediction," Expert Systems with Applications, vol. 37, no. 2, pp. 1784-1789, 2010.

[15] Y. Y. Cao, "Modeling for grey forecasting of calamities in geography," Youthgeogrnphers, vol. 2, pp. 6-11, 1987.

[16] S. An, J. Yan, and X. Yu, "Grey-system studies on agricultural ecoengineering in the Taihu lake area, Jiangsu, China," Ecological Engineering, vol. 7, no. 3, pp. 235-245, 1996.

[17] H. V. Trivedi and J. K. Singh, "Application of grey system theory in the development of a runoff prediction model," Biosystems Engineering, vol. 92, no. 4, pp. 521-526, 2005.

[18] W. Gao, Computational Methods in Engineering \& Science, Springer, Berlin, Germany, 2007. 
[19] P. Lu and M. S. Rosenbaum, "Artificial neural networks and grey systems for the prediction of slope stability," Natural Hazards, vol. 30, no. 3, pp. 383-398, 2003.

[20] C. C. Hsu and C. Y. Chen, "Applications of improved grey prediction model for power demand forecasting," Energy Conversion and Management, vol. 44, no. 14, pp. 2241-2249, 2003.

[21] Y. F. Wang, "Predicting stock price using fuzzy grey prediction system," Expert Systems with Applications, vol. 22, no. 1, pp. 3338, 2002.

[22] J. L. Deng, "Introduction to grey system theory," The Journal of Grey System, vol. 1, no. 1, pp. 1-24, 1989.

[23] C. C. Wong, B. C. Lin, and C. T. Cheng, "Fuzzy tracking method with a switching grey prediction for mobile robot," in Proceedings of the 10th IEEE International Conference on Fuzzy Systems, pp. 103-106, Melbourne, Australia, December 2001.

[24] M. N. Papa, V. Medina, F. Ciervo, and A. Bateman, "Estimation of debris flow critical rainfall thresholds by a physically-based model," Hydrology and Earth System Sciences Discussions, vol. 9, no. 11, pp. 12797-12824, 2012.

[25] M. Bacchini and A. Zannoni, "Relations between rainfall and triggering of debris-flow: case study of Cancia (Dolomites, Northeastern Italy)," Natural Hazards and Earth System Science, vol. 3, no. 1-2, pp. 71-79, 2003.

[26] B. Y. Tan and A. Y. Duan, "Study on prediction for rainstorm debris flow along mountain district railway," Journal of Natural Disasters, vol. 4, no. 2, pp. 43-52, 1995 (Chinese).

[27] H. Wu, L. Shao, and D. D. Lu, “The geological calamity and the rainstorm intensity in Lanzhou City," Arid Meteorology, vol. 23, no. 1, pp. 63-67, 2005 (Chinese). 

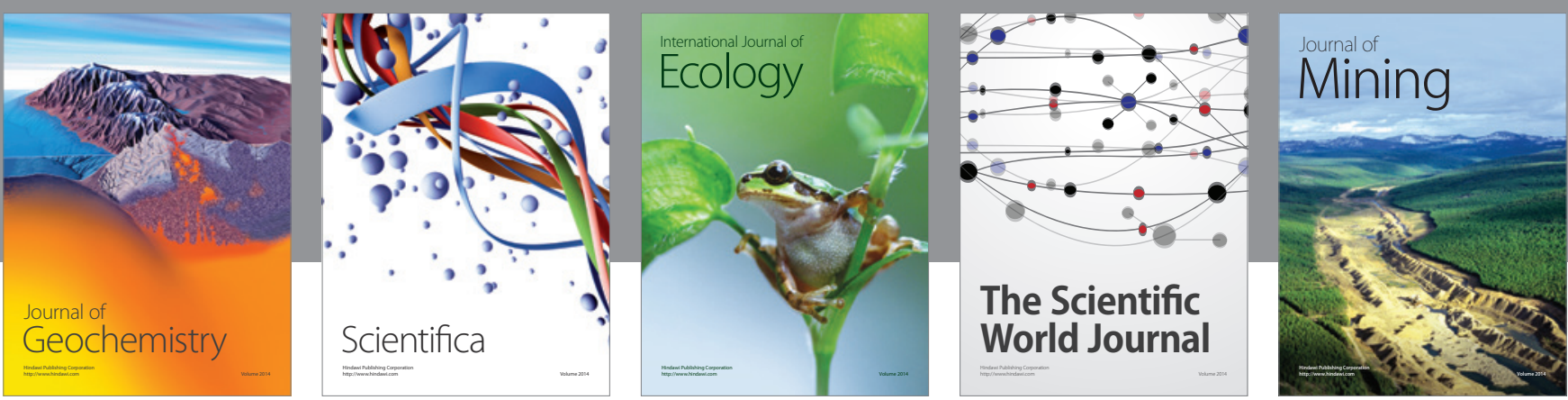

The Scientific World Journal
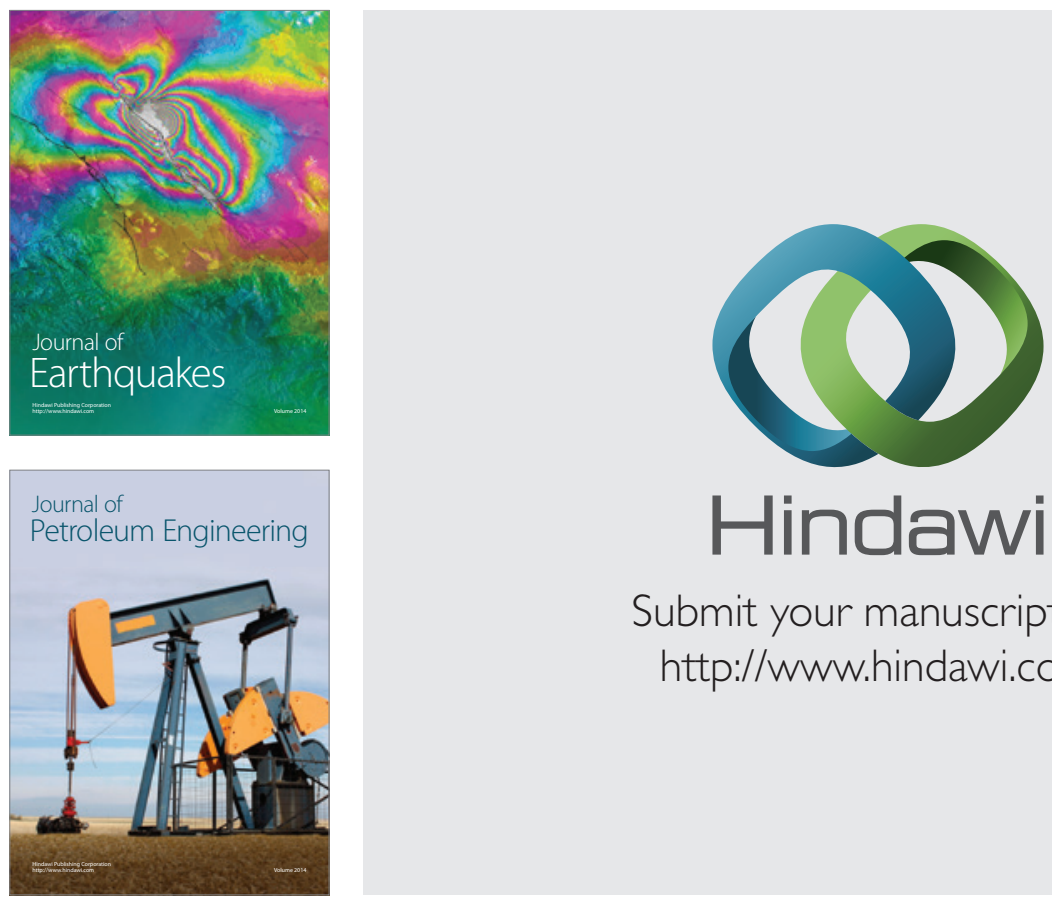

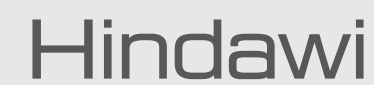

Submit your manuscripts at

http://www.hindawi.com
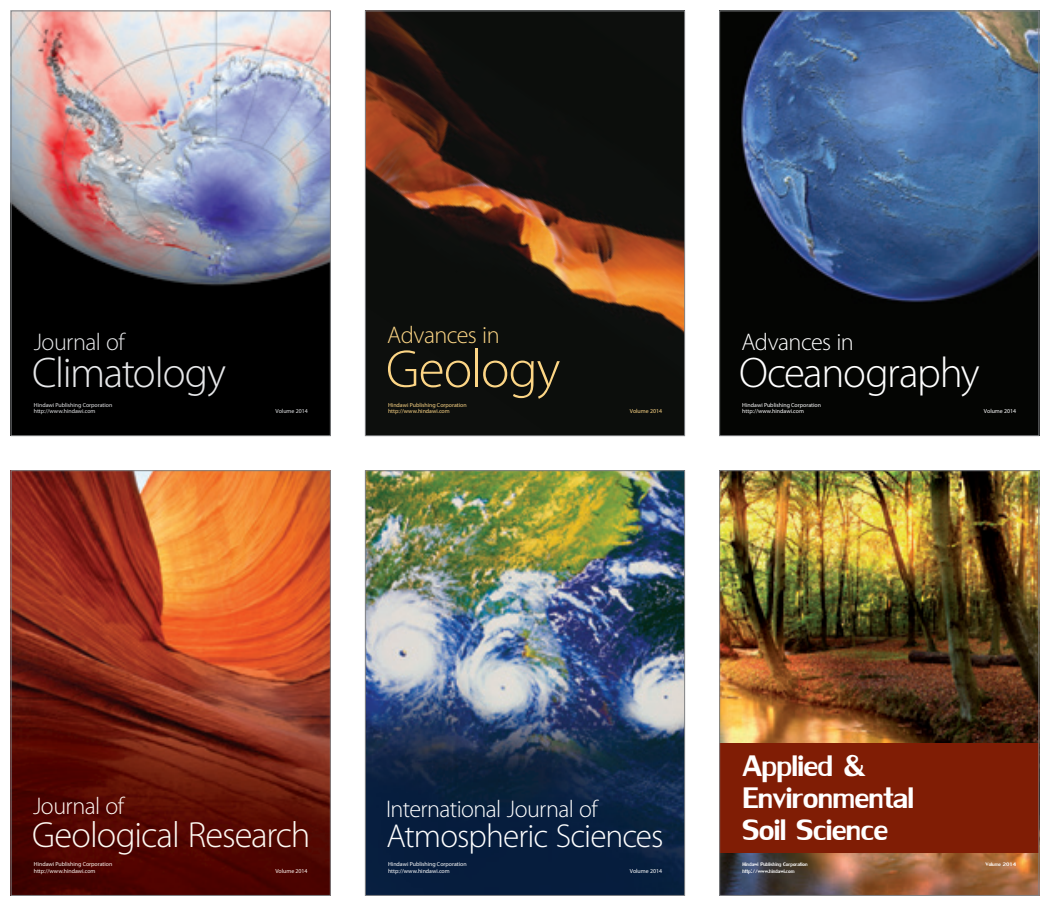
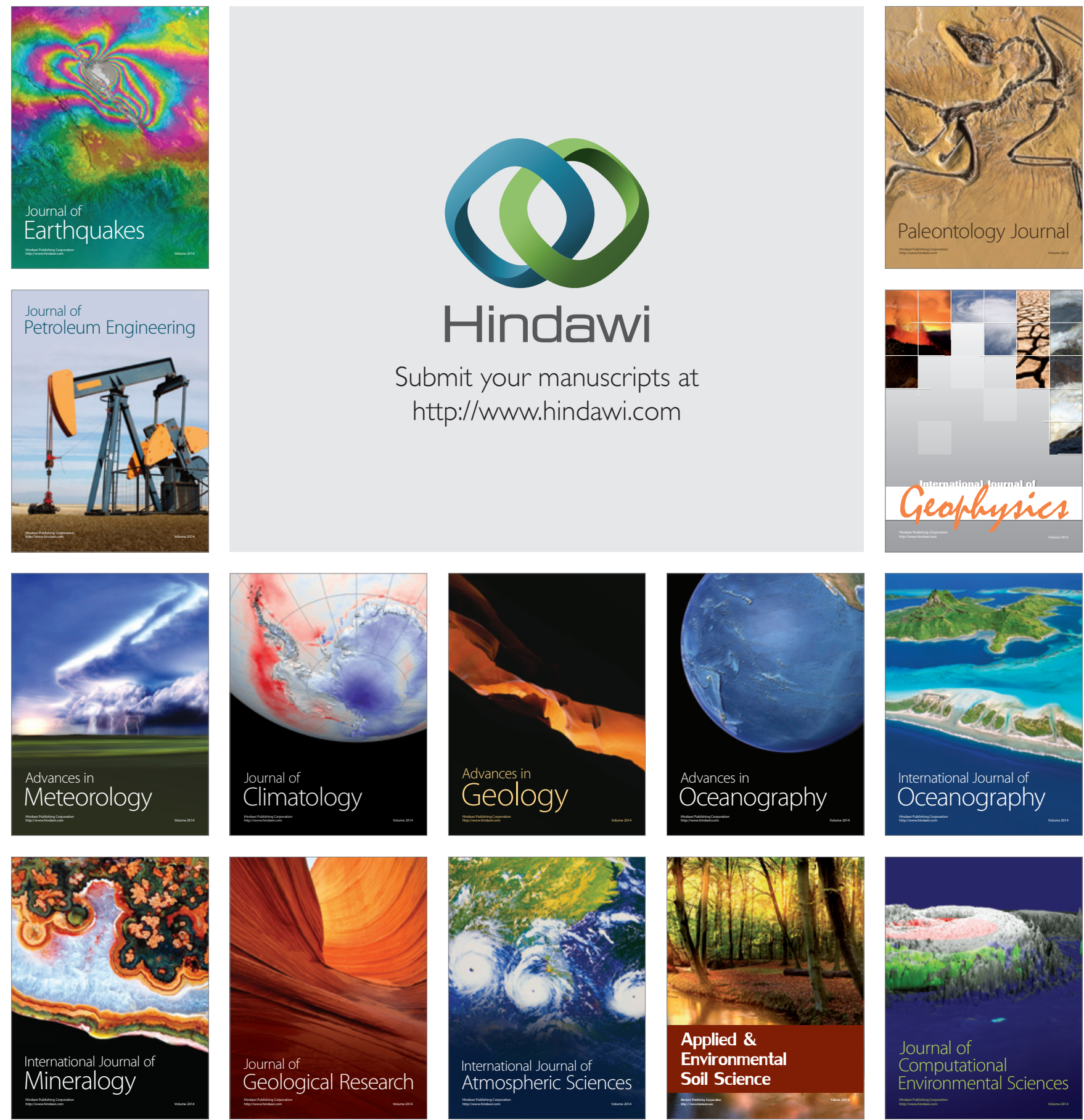